\title{
Effects of static and electromagnetic fields on human serum paraoxonase-1 activity in vitro
}

\author{
Soheila Abdi ${ }^{1 *}$
}

1. Department of Physics, Safadasht Branch, Islamic Azad University, Tehran, Iran

*Corresponding author:Tel: +98 2165432755 Fax: +98 2165433530

Address: Department of Physics, Safadasht Branch, Islamic Azad University, Tehran, Iran

E-mail: abdi.soheila@gmail.com

Received; 2017/11/23 revised; 2017/12/22 accepted; 2018/01/10

\begin{abstract}
Introduction: In recent years the relationship between electromagnetic fields and coronary artery disease is attracted a considerable attention. Low density lipoprotein (LDL) oxidation is the initial step in the development of atherosclerosis. Paraoxonase1 (PON1) protects LDL and High density lipoprotein (HDL) against oxidative processes, thus preventing the formation of atherogenic (oxidized-LDL) ox-LDL molecules. In this study we investigated the effects of static magnetic fields (SMFs) and extremely low frequency electromagnetic fields (ELFEMFs) on PON1 activity as one of the independent risk factors for cardiovascular disease.

Materials and methods: Pooled serum sample of 20 healthy men were exposed to SMFs and EMFs flux densities of $0.125,0.25,0.5,1,2,3$ and $4 \mathrm{mT}$ for 60,120 and 180 minutes at $25^{\circ} \mathrm{C}$ and then PON1 activity was measured spectrophotometrically using paraoxon as substrate.

Results: EMFs of 0.125-1 mT had no effect on PON1 activity. Exposure to magnetic flux density of $2 \mathrm{mT}$ leads to a significant increase in PON1 activity in 1 hour ( $\mathrm{P}<0.05)$. Magnetic flux density of 3 and $4 \mathrm{mT}$, after 1 hour of exposure, lead to an increase of PON1 activity to $1.2 \%$ and $2.8 \%$, respectively $(\mathrm{P}<0.01)$.

Conclusion: PON1 activity is influenced by a variety of agents like environmental, pharmacological, and lifestyle factors as well as age and sex. According to the finding of this study ELF-EMFs can alternate the serum activity of PON1 in vitro. If this effect of EMFs on PON1 activity has proven in vivo, it can be considered as an effective factor in coronary artery disease.
\end{abstract}

Keywords: Static magnetic field, Extremely low frequency electromagnetic field, Paroxonase-1

\section{Introduction}

In today's world, with the progression of technology and continuous exposure of human to a diverse range of electromagnetic fields (EMFs), investigation on the biological effects and health implications of EMFs matters a lot. Meanwhile evaluation of the effects of EMFs on cardiovascular disease (CVD) has attracted considerable attention (1). Coronary artery disease (CAD) is the most common type of CVD, the greatest current public health problem, in the 21st century (2). CAD is a state of degenerative and dynamic alteration in the arterial walls of heart which results from the accumulation of lipids, especially cholesterol and formation of atherosclerosis plaques (3). Among the lipoproteins, high density lipoprotein (HDL) and low density lipoprotein (LDL) play a significant role in atherosclerosis process (4). LDL modification, especially formation of

Copyright (C) 2018 Journal of Basic Research in Medical Science. This is an open access article distributed under the terms of the Creative Commons Attribution 4.0 International License (https://creativecommons.org/licenses/by/4.0/) which permits copy and redistribute the material, in any medium or format, provided the original work is properly cited. 
oxidized LDL (ox-LDL), is an early step in promotion of atherosclerosis which leads to the macrophages accumulation in the arterial wall and transformation in to the foam cells (5). On the other hand, HDL has antioxidant activities (6) and inhibit the oxidation of LDL (7). This antioxidant property of HDL, in part, resulted from the capacity of paraoxonase-1 (PON1), an enzyme associated with HDL structures, to hydrolyze the oxidized phospholipids and hydroxides of cholesteryl linoleate contained in ox-LDL molecules (8). PON1 also limits the process of foam cell formation and reduces the formation of atherosclerotic plaques through suppressing the differentiation of monocytes into macrophages (9).

Decreased PON1 activity has been seen in several diseases such as CAD (10). It is evident that PON1 activity is influenced by a variety of agents like pharmacological, environmental, and lifestyle factors (1113). It is evident that EMFs can influence the activity of enzymes involved various metabolic pathways in plants (14-16), cultured cells (17), and animals (18).

Investigation on rats shown that exposure to extremely low frequency magnetic fields (ELF-MF) could impair oxidantantioxidant function and might increase oxidative stress and lipid peroxidation in a time dependent manner (18). The aim of this study is to investigate the effects of static magnetic fields (SMFs) and ELFMFs on human serum PON1 activity in vitro in a common intensities we expose to daily.

\section{Materials and methods}

Serum preparation and enzyme activity assay: A pooled serum was prepared from $12 \mathrm{~h}$ fasting blood samples of 20 donors. Blood samples $(2 \mathrm{ml})$ were collected by venepuncturing after 12-14 $\mathrm{h}$ fasting. Serum was separated by centrifugation at $3000 \mathrm{rpm}$ for $15 \mathrm{~min}$. A $100 \mu \mathrm{l}$ aliquot of serum was stored at $-80^{\circ} \mathrm{C}$ until the measurement of serum PON1 activity. PON1 activity was determined using $2 \mathrm{mM}$ paraoxon (diethyl p-nitro-phenyl phosphate, Sigma chemical Co., USA) as the substrate in $100 \mathrm{mM}$ tris buffer, $\mathrm{pH} 8.0$, containing $2 \mathrm{mM}$ of $\mathrm{CaCl} 2$. A $40 \mu \mathrm{l}$ aliquot of pooled serum was added to $500 \mu$ of the substrate medium. The generation of $\mathrm{p}$ nitrophenol (initial rate of hydrolysis) was determined at $412 \mathrm{~nm}$ using UV-VIS-3100 spectrophotometer (Shimadzu, Kyoto, Japan) over a period of $2 \mathrm{~min}$ (19). The molar extinction coefficient of $\mathrm{p}$ nitrophenol was considered $17,000 \mathrm{M} / \mathrm{cm}$ (20). All assays were performed in duplicate at $25^{\circ} \mathrm{C}$. The between assay and within assay coefficient of variation $(\mathrm{CV})$ for the method was $3.6 \%$ and $5.1 \%$, respectively.

SMF and EMF Exposure System: A solenoid cylinder with a diameter of $12 \mathrm{~cm}$, height of $30 \mathrm{~cm}$, and 1200 turns was used to generate SMF and EMF. For producing suitable static magnetic flux densities, a regulated direct current (DC) power supply (Model 7321, Sanjesh, Tehran, Iran) and for producing suitable electromagnetic flux densities, a voltage regulator $\mathrm{AC}$ power supply (model: TDGC2, 220v, 50-60 Hz, Delta International Electric Co, Shanghai, China) have been applied. The solenoid was located inside a $25^{\circ} \mathrm{C}$ ventilated incubator (Parsazma, Tehran, Iran), so the temperature inside the solenoid was controlled exactly during the exposure. Before enzyme activity measurement, serum samples (inside a quartz cuvette) were put in the centre of the solenoid for certain times. The produced SMF and EMF at the exact site of cuvette location was measured using a digital teslameter with a 3-D sensor (Holaday, Eden Prairie, MN) $(21,22)$.

\section{Statistics analysis}

Statistical analysis was performed using SPSS 16.0 (SPSS Inc., Chicago, IL). The results are presented as mean values \pm standard deviation. A probability of 0.05 was considered statistically significant. Non-parametrical Mann-WhitneyWilcoxon test was used to compare the data 
between control and exposed samples. Comparison of data between different magnetic flux densities and different exposure times was examined with the non-

\section{Results}

The impact of SMFs of $0.125,0.5,1,2,3$ and $4 \mathrm{mT}$ on serum PON1 activity is shown in Table1. Static magnetic flux density of $0.125 \mathrm{mT}$ had no effect on PON1 activity. Static magnetic flux densities of 0.25 and $0.5 \mathrm{mT}$ lead to an increase $(8.1 \%$ and $1.7 \%$, respectively) in PON1 activity at the first hour of exposure. Exposure of serum to 1 parametric Kruskal-Wallis H-test for several independent samples.

mT SMF for 3 hours decreased the PON1 activity to $1.7 \%(\mathrm{P}<0.05)$. As indicated in Table 1, PON1 activity significantly increased only at the first hour of exposure to $2 \mathrm{mT}$ SMF (P <0.05). SMFs of 3 and 4 $\mathrm{mT}$ lead to the increase in PON1 activity in all applied times of exposure.

Table1. Effect of SMFs on serum PON1 activity after 3 hours of exposure.

\begin{tabular}{lcccc}
\hline & \multicolumn{4}{c}{ Time of exposure $(\mathrm{min})$} \\
\cline { 2 - 5 } SMF $(\mathrm{mT})$ & 0 & 60 & 120 & 180 \\
\hline 0.125 & $77.93 \pm 0.68$ & $77.82 \pm 0.5$ & $78.56 \pm 0.23$ & $78.26 \pm 0.4$ \\
0.25 & $77.40 \pm 0.4$ & $83.66 \pm 0.87^{* *}$ & $82.01 \pm 0.35^{* *}$ & $83.83 \pm 0.51^{* *}$ \\
0.5 & $77.85 \pm 0.4$ & $79.21 \pm 0.58^{*}$ & $80.32 \pm 0.61^{* *}$ & $79.82 \pm 0.61^{* *}$ \\
1 & $78.09 \pm 0.41$ & $78.42 \pm 0.42$ & $77.94 \pm 0.18$ & $76.77 \pm 0.68^{*}$ \\
2 & $78.27 \pm 0.42$ & $79.26 \pm 0.33^{*}$ & $78.07 \pm 0.45$ & $77.48 \pm 0.28$ \\
3 & $78.15 \pm 0.38$ & $82.55 \pm 0.33^{* *}$ & $82.49 \pm 0.30^{* *}$ & $80.25 \pm 0.24^{* *}$ \\
4 & $78.45 \pm 1.34$ & $87.41 \pm 0.35^{* *}$ & $83.35 \pm 0.38^{* *}$ & $82.51 \pm 0.40^{* *}$ \\
\hline
\end{tabular}

Serum PON1 activity was determined using paraoxon as substrate at $25^{\circ} \mathrm{C}$ within two minutes. The data shows the level of PON1 activity in U/l and the values expressed as mean \pm standard derived from the five separate tests. ${ }^{*} \mathrm{P}<0.05,{ }^{* *} \mathrm{P}<0.01$

The impact of extremely low frequency EMFs of $0.125,0.5,1,2,3$ and $4 \mathrm{mT}$ on serum PON1 activity is indicated in Table 2. Electromagnetic flux densities of 0.125 to $1 \mathrm{mT}$ had no effect on PON1 activity even after 3 hours of exposure. Magnetic flux density of $2 \mathrm{mT}$ increases the activity of PON1 just at the first hour of exposure $(\mathrm{P}<0.05)$. The magnetic fields of 3 and 4 $\mathrm{mT}$ result in a significant increase in enzyme activity, reaching a maximum of $1.2 \%$ and $8.2 \%$.

Table2. Effect of EMFs on serum PON1 activity after 3 hours of exposure.

\begin{tabular}{lcccc}
\hline & \multicolumn{4}{c}{ Time of exposure $(\mathrm{min})$} \\
\cline { 2 - 5 } EMF $(\mathrm{mT})$ & 0 & 60 & 120 & 180 \\
\hline 0.125 & $84.63 \pm 0.63$ & $85.0 \pm 0.36$ & $84.96 \pm 0.35$ & $84.83 \pm 0.4$ \\
0.25 & $84.96 \pm 0.57$ & $84.64 \pm 0.61$ & $84.98 \pm 0.51$ & $84.56 \pm 0.44$ \\
0.5 & $85.26 \pm 0.53$ & $85.12 \pm 0.29$ & $84.76 \pm 0.45$ & $84.69 \pm 0.35$ \\
1 & $85.15 \pm 0.49$ & $85.76 \pm 0.51$ & $85.73 \pm 0.40$ & $85.80 \pm 0.34$ \\
2 & $84.75 \pm 0.40$ & $85.93 \pm 0.45^{*}$ & $85.81 \pm 0.50$ & $85.89 \pm 0.29$ \\
3 & $85.31 \pm 0.49$ & $87.09 \pm 0.39^{* *}$ & $87.01 \pm 0.48^{* *}$ & $86.88 \pm 0.43^{* *}$ \\
4 & $85.11 \pm 0.49$ & $87.16 \pm 0.5^{* *}$ & $87.48 \pm 0.45^{* *}$ & $87.51 \pm 0.31^{* *}$ \\
\hline
\end{tabular}

Serum PON1 activity was determined using paraoxon as substrate at $25^{\circ} \mathrm{C}$ within two minutes. The data shows the level of PON1 activity in U/l and the values expressed as mean \pm standard derived from the five separate tests. ${ }^{*} \mathrm{P}<0.05,{ }^{* *} \mathrm{P}<0.01$

\section{Discussion}

This study was undertaken to investigate the effects of SMFs and extremely low frequency EMFs on human serum PON1 activity in vitro. According to the result of our study, SMFs and ELF-EMFs can impact the activity of PON1, although 
changing the activity of PON1 under the SMF doesn't follow a specific pattern and is not dependent on the time of exposure. Exposure to magnetic flux density of $2 \mathrm{mT}$ leads to a significant increase in PON1 activity in 2 hours. Magnetic flux density of 3 and $4 \mathrm{mT}$ lead to an increase in PON1 activity to $1.2 \%$ and $2.8 \%$ after $1 \mathrm{~h}$ of exposure respectively.

The earth's magnetic field is about 0.03 to $0.07 \mathrm{mT}$, which is a natural component of the environment for living organisms. Magnetic fields much weaker than the earth's field can affect living organisms through the chemical processes and effect on the radical pair recombination (23). A review by Belyavskaya suggested that prolonged exposure of plants to a weak magnetic field might cause different biological effects at the cellular, tissue and organ levels (24).

Induction of electrical charges and currents is a primary action of MF in biological systems (25). Influence on nuclear spins of paramagnetic molecules is one of the major molecular effects of MFs which plays an important role in chemical reaction when two molecules with unpaired electrons are formed following the disruption of chemical bound (26).

Study on the impact of electromagnetic fields on the enzymes activity is a new concept in science and there are only a few publications on this subject in accessible literature. Enzymes contain protein structures that organize the dipoles and charges into an especial pattern that can orient specifically the electric field they exert onto particular regions of their bound substrates (27-30). This effect is called electrostatic preorganization. A reorganized enzyme active site can create an electric field with a particular orientation which is controlled by the protein's folded structure and optimizes a particular electrostatic interaction (28).

The impact of a frequent magnetic field on the activity of peroxidase, catalase and superoxide dismutase (respiratory enzymes) was investigated before $(31,32)$.
According to the report of Seifirad et al, acute ELF-MF exposure increased lipid peroxidation and antioxidant serum activity (PON1 activity) in rat. These changes are irreversible in chronic exposure. They believe that the effects of ELF-MF evoke antioxidant system to recompense toxic effects of produced reactive oxygen species (18).

Shaoyi et al, investigate the effects of magnetic field on the activity of $\alpha$-amylase purified from Bacillus subtilis. They report that magnetic field had a considerable effect on activity, $\mathrm{Km}, \mathrm{Vm}$ and secondary conformation of $\alpha$-amylase in a dose and time dependent manner. The values of $\mathrm{Km}$ and $\mathrm{Vm}$ reduced with increase in the intensity of magnetic field (33).

\section{Conclusion}

ELF- MF exposure could impair oxidant antioxidant balance and might increase oxidative stress and lipid peroxidation. Antioxidant defect could be repaired after exposure; however it might depends on the duration and continuity of ELF-MF exposure. This investigation indicates that PON1 activity can affected by static and electromagnetic fields in vitro, whereas increases of magnetic field intensity and exposure time do not cause linear increases for PON1 activity. The possible reason for change in PON1 activity and kinetic parameters may be the secondary conformation changed in enzyme structure following the exposure to static and electromagnetic fields.

\section{Acknowledgment}

Author would like to thanks Dr. Amirnader Emami Razavi for his valuable helps and also appreciates all subjects who participate in this research.

\section{Conflict of interest}

Authors declare that there is no conflict of interest. 


\section{References}

1. McNamee DA, Legros AG, Krewski DR, Wisenberg G, Prato FS, Thomas AW. A literature review: the cardiovascular effects of exposure to extremely low frequency electromagnetic fields. Int. Arch. Occup. Environ. Health. 2009;82(8):919-33.

2. Gauld R, Blank R, Burgers J, Cohen AB, Dobrow M, Ikegami N, et al. The World Health Report 2008-Primary Healthcare: How Wide Is the Gap between Its Agenda and Implementation in 12 High-Income Health Systems? Healthc Policy. 2012;7(3):38.

3. Kowalska K, Socha E, Milnerowicz H. the role of paraoxonase in cardiovascular diseases. Ann Clin Lab Sci. 2015;45(2):226-33.

4. Skoczyńska A. Rola lipidów w powstawaniu miażdżycy The role of lipids in atherogenesis. Postepy Hig Med Dosw(online). 2005;59:346-57.

5. Yoshida H, Kisugi R. Mechanisms of LDL oxidation. Clin. Chim. Acta. 2010;411(23):1875-82.

6. Kuliszkiewicz-Janus M, Mohamed AS, Abod N. Biologia lipoproteiny HDL i jej przeciwmiażdżycowe działanie The biology of HDL lipoprotein and its antisclerotic activity. Postepy Hig Med Dosw(online). 2006;60:307-15.

7. Norata GD, Pirillo A, Catapano AL. Modified HDL: biological and physiopathological consequences. Nutr Metab Cardiovasc Dis. 2006;16(5):37186.

8. Zielaskowska J, Olszewska-Slonina D. The polymorphism of paraoxonase and its effects in physiological and pathological processes. Adv Clin Exp Med. 2006;15(6):1073.

9. Berrougui $\mathrm{H}$, Loued $\mathrm{S}$, Khalil A. Purified human paraoxonase-1 interacts with plasma membrane lipid rafts and mediates cholesterol efflux from macrophages. Free Radic Biol Med. 2012;52(8):1372-81.

10. Fridman O, Fuchs A, Porcile R, Morales A, Gariglio L. Paraoxonase: its multiple functions and pharmacological regulation. Arch Cardiol Mex. 2010;81(3):251-60.

11. Costa LG, Vitalone A, Cole TB, Furlong CE. Modulation of paraoxonase (PON1) activity. Biochem. Pharmacol. 2005;69(4):541-50.

12. Ferré N, Camps J, Fernandez-Ballart J, Arija V, Murphy MM, Ceruelo S, et al. Regulation of serum paraoxonase activity by genetic, nutritional, and lifestyle factors in the general population. Clin. Chem. 2003;49(9):1491-7.

13. Sutherland WH, Walker RJ, de Jong SA, van Rij AM, Phillips V, Walker HL. Reduced postprandial serum paraoxonase activity after a meal rich in used cooking fat. Arterioscler Thromb Vasc Biol. 1999;19(5):1340-7.

14. Çelik Ö, Büyükuslu N, Atak Ç, Rzakoulieva A. Effects of Magnetic Field on Activity of Superoxide Dismutase and Catalase in Glycine max (L.) Merr. Roots. Pol J Environ Stud. 2009;18(2).

15. Peyvandi M, Khaledi NK, Arbabian S. The effects of magnetic fields on growth and enzyme activities of Helianthus annuus L. seedlings'. Iranian Journal of Plant Physiology. 2013;3(3):717-24.

16. Rochalska M, Grabowska K. Influence of magnetic fields on the activity of enzymes: alpha-and beta-amylase and glutathione S-transferase (GST) in wheat plants. Int Agrophys. 2007;21(2): 185 .

17. Sahebjamei H, Abdolmaleki P, Ghanati F. Effects of magnetic field on the antioxidant enzyme activities of suspension-cultured tobacco cells. Bioelectromagnetics. 2007;28(1):42-7. 
18. Seifirad S, Farzampour S, Nourbakhsh M, Amoli MM, Razzaghy-Azar M, Larijani B. Effects of extremely low frequency electromagnetic fields on paraoxonase serum activity and lipid peroxidation metabolites in rat. $\mathbf{J}$ Diabetes Metab Disord. 2014;13(1):85.

19. Razavi AE, Ani M, Pourfarzam M, Naderi GA. Associations between high density lipoprotein mean particle size and serum paraoxonase-1 activity. J Res Med Sci. 2012;17(11):1020.

20. Troughton J, Woodside J, Yarnell J, Arveiler D, Amouyel P, Ferrieres J, et al. Paraoxonase activity and coronary heart disease risk in healthy middleaged males: the PRIME study. Atherosclerosis. 2008;197(2):556-63.

21. Abdi S, Dorranian D, Naderi GA, Razavi AE. Changes in physicochemical charachteristics of human low density lipoprotein nano-particles by electromagnetic field exposure. Studia Universitatis Babes-Bolyai, Chemia. 2016;61(1): 185-97.

22. Abdi S, Dorranian D, Razavi AE, Naderi GA, Boshtam M, Ghorannevis M. Evaluation of the effects of weak and moderate static magnetic fields on the characteristics of human low density lipoprotein in vitro. Bioelectromagnetics. 2013;34(5):397404.

23. Adair RK. Effects of very weak magnetic fields on radical pair reformation. Bioelectromagnetics. 1999;20(4):255-63.

24. Belyavskaya N. Biological effects due to weak magnetic field on plants. Advances in space Research. 2004;34(7):1566-74.

25. Roy C, Repacholi M. Electromagnetic field and health, a WHO perspective. World Health Organization, Geneva, Switzerland Available from: http://www worldaluminium org/news/montreal/roy htm. 2005.

26. Zmyślony M, Palus J, Jajte J, Dziubaltowska E, Rajkowska E. DNA damage in rat lymphocytes treated in vitro with iron cations and exposed to 7 mT magnetic fields (static or $50 \mathrm{~Hz}$ ). Mutat Res-Fund Mol Mech Mut. 2000;453(1):89-96.

27. Warshel A. Energetics of enzyme catalysis. Proc. Natl. Acad. Sci. U.S.A. 1978;75(11):5250-4.

28. Warshel A. Calculations of enzymic reactions: calculations of $\mathrm{pKa}$, proton transfer reactions, and general acid catalysis reactions in enzymes. Biochem. 1981;20(11):3167-77.

29. Warshel A, Levitt M. Theoretical studies of enzymic reactions: dielectric, electrostatic and steric stabilization of the carbonium ion in the reaction of lysozyme. J. Mol. Biol. 1976;103(2):227-49.

30. Warshel A, Sharma PK, Kato M, Xiang Y, Liu H, Olsson MH. Electrostatic basis for enzyme catalysis. Chem. Rev. 2006;106(8):3210-35.

31. Tugulea L, Miclaus S, Pascanu S, editors. Chlorophyll A- a suitable biomaterial for monitoring the electromagnetic influence at molecular level. 22 Annual Meeting Eur Bioelectromagnetics Association, Munich, Germany; 2000.

32. Xi G, Fu Z. Effect of external magnetic field on peroxidase synthesis and its activation during germination in wheat. Journal of Plant Physiology and Molecular Biology. 1992;19(2):155-61.

33. Jia S, Liu Y, Wu S, Wang Z. Effect of static magnetic field on $\alpha$-amylase activity and enzymatic reaction. Transactions of Tianjin University. 2009; 15(4):272-5. 